Article

\title{
Benzothiazole Nickelation: An Obstacle to the Catalytic Arylation of Azoles by Cyclopentadienyl Nickel N-Heterocyclic Carbene Complexes
}

\author{
Saurabh Shahane ${ }^{1}$, Bernardo de P. Cardoso ${ }^{1}$, Michael J. Chetcuti ${ }^{1, *}$ and Vincent Ritleng ${ }^{1,2, *(D)}$ \\ 1 Université de Strasbourg, Ecole Européenne de Chimie, Polymères et Matériaux, CNRS, LIMA, UMR 7042, \\ 67000 Strasbourg, France; shahane.saurabh@gmail.com (S.S.); bernardo.cardos0@etu.unistra.fr (B.d.P.C.) \\ 2 Institut Universitaire de France, 75000 Paris, France \\ * Correspondence: michael.chetcuti@unistra.fr (M.J.C.); vritleng@unistra.fr (V.R.); Tel.: +33-3-6885-2797 (V.R.)
}

Received: 20 December 2018; Accepted: 9 January 2019; Published: 12 January 2019

check for updates

\begin{abstract}
NiCp}^{\dagger} \mathrm{L}(\mathrm{NHC})\right]^{(+)}$complexes $\left(\mathrm{Cp}^{\dagger}=\mathrm{Cp}\left(\eta^{5}-\mathrm{C}_{5} \mathrm{H}_{5}\right), \mathrm{Cp}^{*}\left(\eta^{5}-\mathrm{C}_{5} \mathrm{Me}_{5}\right) ; \mathrm{NHC}=\mathrm{N}\right.$-heterocyclic carbene; $\mathrm{L}=\mathrm{Cl}^{-}$or NCMe) have been tested as pre-catalysts for the direct arylation of benzothiazole in the presence of an alkoxide. Only the pentamethylcyclopentadienyl derivative, [ $\left.\mathrm{NiCp}{ }^{*} \mathrm{Cl}(\mathrm{IMes})\right]$ (IMes = 1,3-bis(2,4,6-trimethylphenylimidazol-2-ylidene), enabled low conversion to the desired coupling product with phenyl iodide as the electrophilic coupling partner. In contrast, all cyclopentadienyl complexes proved to be inactive. ${ }^{1} \mathrm{H}$ NMR studies of the "catalytic" reaction mixtures demonstrate that they cleanly convert to an unreactive C(2)-benzothiazolyl derivative, whose identity has been confirmed by an independent synthesis and characterization. The latter constitutes a potential energy well that quenches all further reactivity, and provides a rare example of $C(2)$-metallated azolyl complex.
\end{abstract}

Keywords: azole arylation; azolyl trapping; benzothiazolyl complex; nickel; N-heterocyclic carbene

\section{Introduction}

The recent trend to use $3 \mathrm{~d}$ transition metal catalysts, that is driven by economic and environmental concerns, has led to a re-assessment of nickel's reactivity [1-4]. In particular, nickel catalysts have emerged as promising candidates for $\mathrm{C}-\mathrm{H}$ bond functionalization [5-8], and nickel-catalyzed reactions between (hetero)arenes and aryl halides [9-12], phenol derivatives [13-18], aryl or alkenyl esters [19-21] or even alkyl halides [22,23] have been shown to be reliable atom-economical alternatives to palladium-catalyzed cross-couplings. In this context, we have recently reported that the unsaturated T-shaped nickelacycle 1, that bears a mono-anionic C,C-NHC-cyanoalkyl chelate (NHC = $\mathrm{N}$-heterocyclic carbene), shows moderate activity for the coupling of benzothiazole with aryl iodides (Scheme 1) [24]. In contrast, the corresponding cyclopentadienyl nickelacycle 2 that does not possess any potentially available free coordination sites, unless an eventual Cp ring slippage occurs [25,26], proved totally unreactive under the same conditions (Scheme 1). This suggested to us that an unsaturated nickel center and/or labile ligands were necessary to observe benzothiazole arylation [24]. We therefore wondered whether $\mathrm{Cp}^{\dagger} \mathrm{Ni}\left[\mathrm{Cp}^{\dagger}=\mathrm{Cp}\left(\eta^{5}-\mathrm{C}_{5} \mathrm{H}_{5}\right), \mathrm{Cp}^{*}\left(\eta^{5}-\mathrm{C}_{5} \mathrm{Me}_{5}\right)\right]$ complexes bearing a monodentate NHC ligand as well as a readily labile halide or acetonitrile ligand could catalyze such direct biaryl couplings. This family of complexes has indeed been proven to constitute a very versatile class of pre-catalysts [27-33] that notably catalyze the $\alpha$-arylation of ketones [34]. Herein, we report our findings, which show that, under the typical conditions used for the direct coupling of azoles with aryl halides or pseudo-halides (i.e.: under harsh reaction conditions with an alkoxide base $[5,9,10,12,24])$, apart from a $\mathrm{Cp}^{*}$ derivative which shows a little activity with aryl iodides, these complexes form a stable C(2)-nickelated azolyl complex that arrests any further reactivity. 


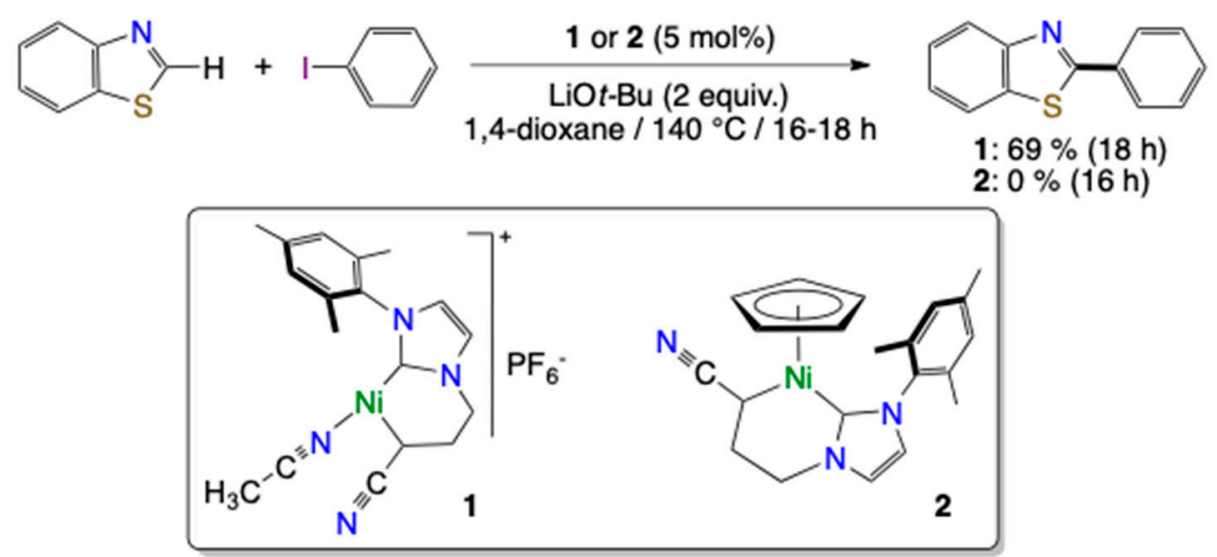

Scheme 1. Coupling of benzothiazole with iodobenzene catalyzed by $\mathbf{1}$ or $\mathbf{2}$ [24].

\section{Results and Discussion}

\subsection{Catalytic Studies}

Four half-sandwich $\mathrm{Ni}(\mathrm{NHC})$ complexes, which have already been demonstrated to catalyze a variety of reactions [27-33], were chosen for the present study: complexes 3 [35-37] and 4 [27,37] bearing a Cp ring, a chloride and, respectively, the 1,3-bis(2,4,6-trimethylphenylimidazol-2-ylidene (IMes) and 1,3-bis(2,6-diisopropylphenylimidazol-2-ylidene (IPr) as NHC ligands, complex 5 [38], the $\mathrm{Cp}^{*}$ analogue of 3 , and complex $\mathbf{6}$ [29], the cationic analogue of $\mathbf{3}$ that bears a labile acetonitrile ligand instead of a chloride (Figure 1).
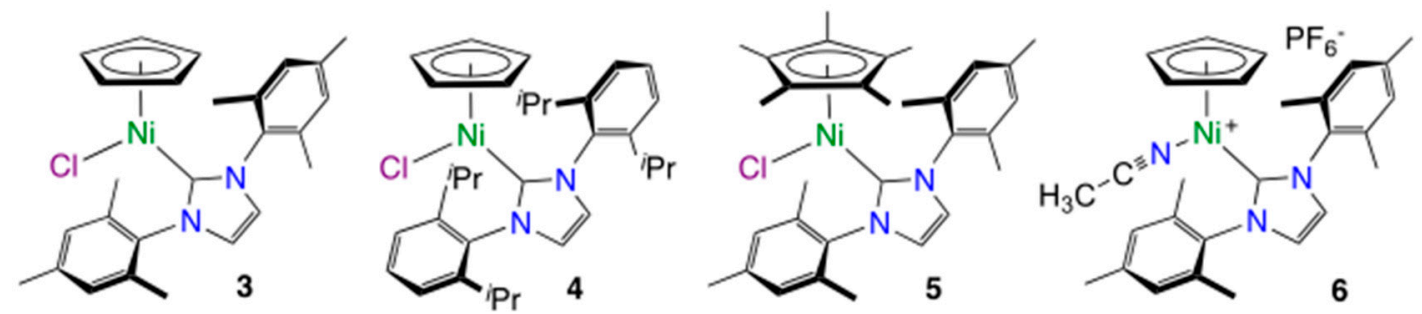

Figure 1. Selected $\mathrm{Cp}^{\dagger}-\mathrm{Ni}(\mathrm{NHC})$ complexes.

Catalytic attempts focused on the reaction of benzothiazole with $p$-bromotoluene or iodobenzene under conditions similar to those established for complex $\mathbf{1}$ [24] and Itami's $\mathrm{Ni}(\mathrm{OAc})_{2} /$ bipyridine or 1,1'-bis(diphenyphosphino)ferrocene system [9,12], i.e.: in 1,4-dioxane at $120-140{ }^{\circ} \mathrm{C}$ in the presence of LiOtBu (1.5-2 equiv.) and $5 \mathrm{~mol} \%$ of 3-6 for $16 \mathrm{~h}$ (Table 1 ). No conversion to the desired hetero-biaryl compound was observed with 3 with either $p$-bromotoluene or iodobenzene (entries 1 and 2), and variations of the base $\left(\mathrm{NaOtBu}, \mathrm{KO} t \mathrm{Bu}, \mathrm{Cs}_{2} \mathrm{CO}_{3}\right.$ or $\left.\mathrm{KOAc}\right)$ and solvent (toluene or THF) gave no better results (not shown in Table 1). Similarly, the other two Cp complexes 4 and $\mathbf{6}$ did not catalyze the coupling of benzothiazole and iodobenzene under such reaction conditions (entries 3 and 5). Only the more electron-rich and more sterically crowded Cp* complex 5 enabled a conversion of $13 \%$ at $140{ }^{\circ} \mathrm{C}$ (entry 4). However, this was still far from the activity observed with complex 1 (Scheme 1) that proved to have a narrow reaction scope and showed a very moderate activity with most substrates [24].

As we were intrigued by the incapacity of the $\mathrm{CpNi}(\mathrm{NHC})$ complexes to catalyze these direct couplings, we attempted to establish the fate of the latter under the reaction conditions. To our surprise, the ${ }^{1} \mathrm{H}$ NMR spectra of the reaction media (after removal of the insoluble and volatiles-see Section 3) of reactions run with 3 under various conditions of solvent (THF, toluene or 1,4-dioxane), base $\left(\mathrm{LiO} t \mathrm{Bu}, \mathrm{NaO} t \mathrm{Bu}, \mathrm{KO} t \mathrm{Bu}\right.$ ) and temperature (from 90 to $140{ }^{\circ} \mathrm{C}$ ) systematically indicated the presence of unreacted benzothiazole and $p$-bromotoluene or iodobenzene, as well as the full and clean 
conversion of 3 to a novel $\mathrm{CpNi(IMes)} \mathrm{complex} 7$ bearing a C(2)-metallated benzothiazolyl group (see Figures S1 and S2, and Scheme 2), whose identity was confirmed by an independent synthesis (vide infra). The latter was indeed characterized by typical signals for its IMes and Cp groups, but which are shifted compared to those of 3 , as well as by two apparent triplets centered at 7.11 and $6.97 \mathrm{ppm}$, which integrate for one proton each relative to the Cp and IMes signals and correspond to the $\mathrm{H}(5)$ and $\mathrm{H}(6)$ protons of a benzothiazolyl unit. However, the signals of the $\mathrm{H}(4)$ and $\mathrm{H}(7)$ overlapped with those of unreacted benzothiazole and were not unambiguously observed. Complex 7 was also observed in the attempted couplings with the cationic complex 6 (Figure S3), highlighting a general behaviour for these $\mathrm{CpNi}(\mathrm{NHC})$ species thereof.

Table 1. Attempted coupling of benzothiazole with $p$-bromotoluene or iodobenzene in the presence of $\left[\mathrm{NiCp}^{\dagger} \mathrm{L}(\mathrm{NHC})\right]^{(+)}$complexes. $^{1}$

\begin{tabular}{ccccc}
\hline & & & [Ni] (5 mol\%) \\
Entry & Catalyst & $\mathrm{X}$ & $\mathrm{R}$ & Conv. $[\%]^{2}$ \\
\hline $1^{3}$ & 3 & $\mathrm{Br}$ & $\mathrm{Me}$ & 0 \\
2 & 3 & $\mathrm{I}$ & $\mathrm{H}$ & 0 \\
$3^{4}$ & 4 & $\mathrm{I}$ & $\mathrm{H}$ & 0 \\
4 & 5 & $\mathrm{I}$ & $\mathrm{H}$ & 13 \\
5 & 6 & $\mathrm{I}$ & $\mathrm{H}$ & 0
\end{tabular}

1 Reaction conditions: benzothiazole (1 equiv.), $p$-bromotoluene or iodobenzene (1.5 equiv.), LiOtBu (2 equiv.), $3-6$ ( $5 \mathrm{~mol} \%$ ) in 1,4-dioxane at $140^{\circ} \mathrm{C}$ for $16 \mathrm{~h}^{2}$ Conversion to the desired coupling product established by GC; average value of two runs. ${ }^{3}$ Run at $120{ }^{\circ} \mathrm{C} .{ }^{4}$ Run with 1.5 equiv. of $\mathrm{LiO} t \mathrm{Bu}$.

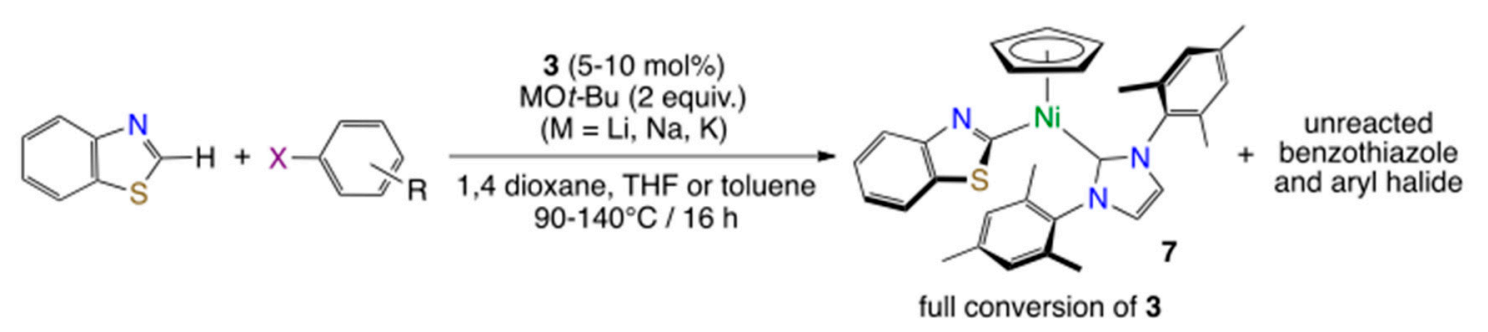

Scheme 2. Benzothiazolyl trapping under catalytic conditions.

Interestingly, although C(2)-benzoxazolyl or benzothiazolyl complexes are often proposed as intermediates in $\mathrm{C}-\mathrm{H} / \mathrm{C}-\mathrm{X}$ couplings between heteroarenes and aryl, alkenyl or alkyl electrophiles $[5,10,12,14,16,17,19,20,22,23]$, they remain very rare. We are indeed aware of only four related PCN-Pd [39-41] and NNN-Ni [23] pincer species, which have been isolated with a benzothiazolyl ligand and demonstrated to be intermediates in similar couplings. Thus, although it obviously constitutes a potential energy well, complex $\mathbf{7}$ is an interesting example of azolyl trapping in such (attempted) direct coupling. Furthermore, it is to our knowledge only the second C(2)-benzothiazolyl-nickel species reported to date [23].

\subsection{Independent Synthesis and Characterization of the Benzothiazolyl Complex 7}

To confirm the identity of 7 , complex 3 was treated with a small excess of benzothiazole (1.2 equiv.) in the presence of potassium bis(trimethylsilyl)amide (KHMDS) as a base in toluene at room temperature (Scheme 3). The resulting complex was isolated in $80 \%$ yield as an air-stable green-brown powder after work-up. Full characterization by ${ }^{1} \mathrm{H}$ and ${ }^{13} \mathrm{C}\left\{{ }^{1} \mathrm{H}\right\} \mathrm{NMR}$, HRMS spectroscopies and CHN microanalyses confirmed the expected formulation. Thus, for instance, the ${ }^{1} \mathrm{H}$ NMR spectrum of 7 no longer displays the $\mathrm{H}(2)$ proton of benzothiazole, but displays the $\mathrm{H}(5)$ and $\mathrm{H}(6)$ protons as two 
apparent triplets at 7.12 and $6.98 \mathrm{ppm}$, as seen in the spectra of the catalytic attempts (vide supra), and the $\mathrm{H}(4)$ and $\mathrm{H}(7)$ protons as two doublets at 7.58 and $7.51 \mathrm{ppm}$ (Figure S4). The Cp and IMes protons are found at values that are typical for $\mathrm{NiCp}$ (IMes) compounds [27-33,35-37]. Regarding the ${ }^{13} \mathrm{C}\left\{{ }^{1} \mathrm{H}\right\}$ NMR spectrum, the C(2) carbon of the benzothiazolyl moiety is observed at $176.0 \mathrm{ppm}$, which is significantly downfield compared to the corresponding carbon of free benzothiazole (153.8 ppm) [42], and thus confirms its metallation (Figure S5) [23]. In addition, it is worth mentioning that the carbene carbon signal of 7 is downfield shifted (177.9 ppm) when compared to that of 3 (165.9 ppm [35]), which suggests a decrease in the Lewis acid character of the metallic center caused by an increase in the $\sigma$-donor ability of the ancillary ligand, [43-46]. This is similar to what is observed with the phenyl and methyl derivatives: [NiCpPh(IMes)] (181.2 ppm) [34] and [NiCpMe(IMes)] (187.4 ppm) [35].

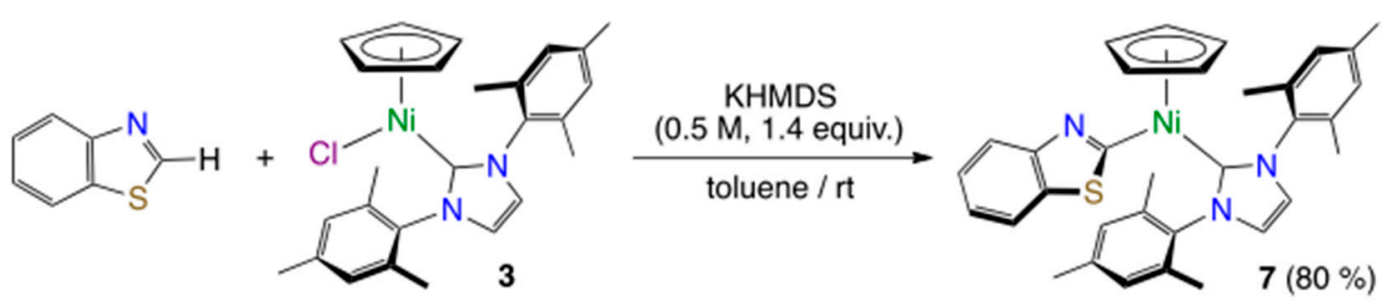

Scheme 3. Independent synthesis of the benzothiazolyl complex 7.

\subsection{Crystallographic Study of $\mathbf{7}$}

The X-ray diffraction study of a single crystal of complex 7 corroborated the NMR data and confirmed the molecule's structure (Figure 2 and Appendix A). Significant bond distances and bond angles are given in Table 2 and crystallographic data and data collection parameters are listed in Table S1. Complex 7 crystallizes in the orthorhombic chiral space group $P 22_{1} 2_{1} 2_{1}$. The Ni-C(1) $[C(1)=$ the carbene carbon atom] and $\mathrm{Ni}-\mathrm{C}(2)$ distances are respectively $1.873(2)$ and $1.875(2) \AA$, which fall slightly below the range observed for related $\mathrm{NiCp}$ (IMes) complexes bearing a third C-bound ligand, such as [NiCp(IMes)Ph] (Ni-C(1): 1.875(2), Ni-C(2): 1.908(2) $\AA$ ) [34] and [NiCp(IMes)(IMe)](BF 4$)$ (Ni-C(1): 1.899(3), Ni-C(2): 1.906(3) $\AA$ ) (IMe = 1,3-dimethylimidazol-2-ylidene) [47]. The Ni-C(2) distance is also significantly shorter than that observed in the only other fully characterized $\mathrm{Ni}-\mathrm{C}(2)-$ benzothiazolyl complex $(1.936(8) \AA)$, that was just reported [23]. The C(1)-Ni-C(2) angle of $94.26(10)^{\circ}$ falls in the same range as observed for [NiCp(IMes)Ph] $\left(95.35(9)^{\circ}\right)$ [34] and [NiCp(IMes)(IMe)] $\left(\mathrm{BF}_{4}\right)\left(96.91(11)^{\circ}\right)$ [47]. Finally, when one takes into account the plane formed by the $C p$ centroid, $C(1)$, and $C(2)$, the nickel atom is almost in a planar environment (Table 2, last entry), as is typically observed in similar two-legged piano-stool $\mathrm{CpNi}(\mathrm{NHC})$ complexes [27-33,35].

Table 2. Key bond distances $(\AA)$ and angles $\left(^{\circ}\right)$ of 7 with Esd's in parentheses.

\begin{tabular}{cc}
\cline { 2 - 2 } Bond or Angle & $\mathbf{7}$ \\
\cline { 2 - 2 } $\mathrm{Ni}-\mathrm{C}(1)$ & $1.873(2)$ \\
$\mathrm{Ni}-\mathrm{C}(2)$ & $1.875(2)$ \\
$\mathrm{Ni}-\mathrm{C} \mathrm{p}_{\mathrm{cent}} 1$ & 1.774 \\
$\mathrm{Ni}-\mathrm{C}_{\mathrm{Cp}}$ av & 2.140 \\
$\mathrm{C}(1)-\mathrm{Ni}-\mathrm{C}(2)$ & $94.26(10)$ \\
$\mathrm{C}(1)-\mathrm{Ni}-\mathrm{C} \mathrm{p}_{\mathrm{cent}}$ & 135.3 \\
$\mathrm{C}(2)-\mathrm{Ni}-\mathrm{C} \mathrm{p}_{\mathrm{cent}}$ & 130.4 \\
$\mathrm{Ni}-\left(\mathrm{C}(1)-\mathrm{C} \mathrm{p}_{\text {cent }}-\mathrm{C}(2)\right)$ & 0.037 \\
${ }^{1} \mathrm{C} \mathrm{p}_{\text {cent }}=$ centroid of the $\mathrm{Cp}$ group. ${ }^{2}$ Average Ni-C distance to the $\mathrm{Cp}$ ring.
\end{tabular}




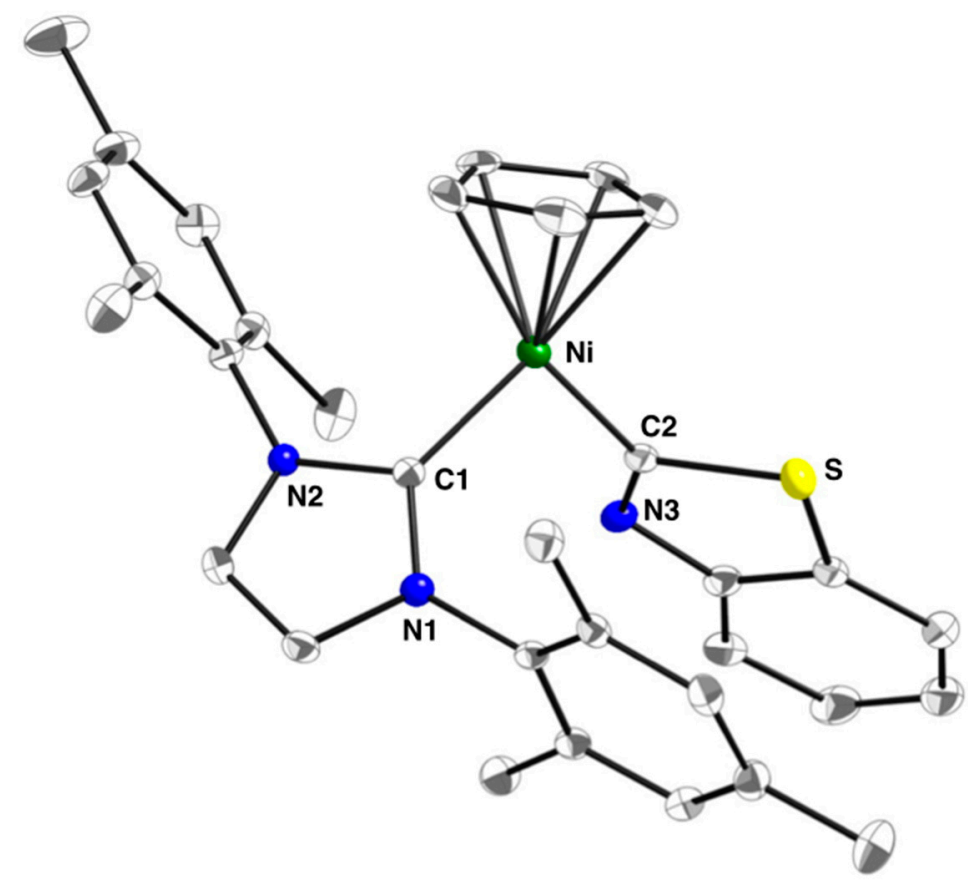

Figure 2. X-ray structure of 7 showing all non-H atoms. Ellipsoids are shown at the $50 \%$ probability level and selected atoms are labelled.

\subsection{Investigation of the Reactivity of the $\mathrm{Cp}^{*}$ Complex 5}

The little activity observed with the $\mathrm{Cp}^{*}$ complex 5 (Table 1, entry 7) raised the question whether the observed coupling reaction goes through a benzothiazolyl complex similar to 7 . To answer this question, complex 5 was treated with benzothiazole and KHMDS similarly to 3 . A quick reaction occurred, but the corresponding benzothiazolyl complex 8 could only be isolated in $12 \%$ yield (Scheme 4) and we have been unable to obtain it analytically pure owing to its relative instability in solution that leads to insoluble materials and/or paramagnetic species. The metallation of benzothiazole was nevertheless confirmed by the absence of the $\mathrm{H}(2)$ proton in the ${ }^{1} \mathrm{H}$ NMR spectrum (Figure S6) and the downfield shift of the $\mathrm{C}(2)$ carbon from 153.8 to $180.9 \mathrm{ppm}$ in the ${ }^{13} \mathrm{C}\left\{{ }^{1} \mathrm{H}\right\} \mathrm{NMR}$ spectrum (Figure S7).

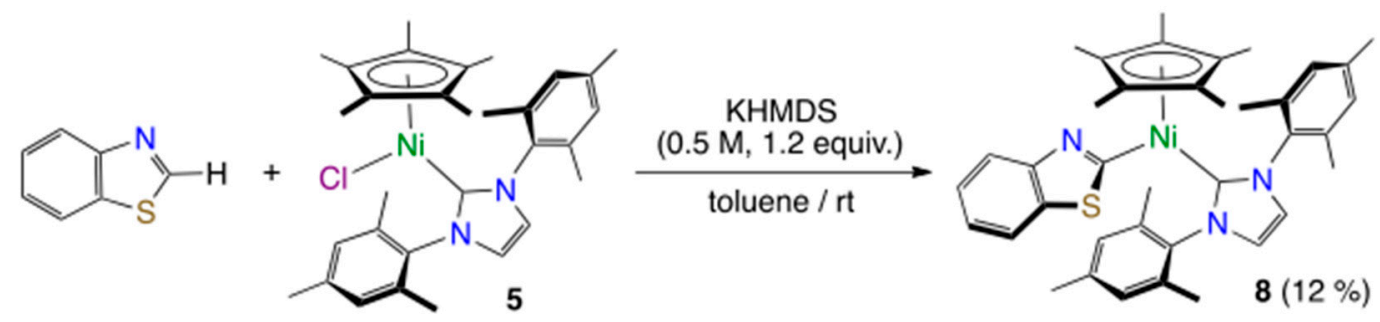

Scheme 4. Synthesis of the Cp* benzothiazolyl complex 8.

Complex 8 was then treated with 1.5 equiv. of iodobenzene in 1,4-dioxane at $140{ }^{\circ} \mathrm{C}$ for $16 \mathrm{~h}$. The reaction led to a massive decomposition of the complex together with a small amount of the expected coupling product ( $<15 \%$ of the identified species) as inferred from the ${ }^{1} \mathrm{H}$ NMR analysis of the crude reaction mixture that shows a very complex mixture. This illustrates the less stable (or more reactive) character of the $C \mathrm{p}^{*}$ derivative 8 , when compared to its $\mathrm{Cp}$ analogue 7 , and suggests the possible involvement of such a benzothiazolyl complex in the coupling reaction [23,39-41], provided that it does not constitute a potential energy well like the Cp derivative 7. 
A possible explanation for the enhanced reactivity of $\mathbf{8}$ may come from both its more electron-rich character, as shown by its downfield shifted carbene carbon in the ${ }^{13} \mathrm{C}\left\{{ }^{1} \mathrm{H}\right\}$ NMR spectrum: $187.4 \mathrm{ppm}$ in 8 vs. 177.9 ppm in 7 [43-46], and its more significant steric crowding. Indeed, in a hypothetic $\mathrm{Ni}(\mathrm{II}) / \mathrm{Ni}(\mathrm{IV})$ catalytic cycle, as proposed by Chatani et al. for a related arylation reaction of $\mathrm{Csp}^{2}-\mathrm{H}$ bonds with aryl iodides [48], the presence of a bulky electron-donating ligand such as $\mathrm{Cp}^{*}$ may (i) favor the oxidative addition of the aryl halide through electronic donation, and (ii) subsequently enhance the reductive elimination of the coupling product due to its steric bulkiness [49]. Further developments of this family of complexes for similar cross-couplings might therefore privilege species with more electron-donating and/or more bulky ligands [50].

\section{Material and Methods}

\subsection{General Comments}

All reactions were carried out using standard Schlenk procedures under an atmosphere of dry argon. Solvents were dried and distilled under argon. Solution NMR spectra were recorded at $298 \mathrm{~K}$ on a Bruker Avance I $300 \mathrm{MHz}$ spectrometer operating at $300.13 \mathrm{MHz}$ for ${ }^{1} \mathrm{H}$ and at $75.47 \mathrm{for}$ ${ }^{13} \mathrm{C}\left\{{ }^{1} \mathrm{H}\right\}$. A DEPT ${ }^{13} \mathrm{C}$ spectrum was recorded for complex 7 to ease the ${ }^{13} \mathrm{C}$ signals assignment. The chemical shifts are referenced to the residual deuterated or ${ }^{13} \mathrm{C}$ solvent peaks. Chemical shifts $(\delta)$ and coupling constants $(J)$ are given in ppm and $\mathrm{Hz}$, respectively. GC analyses were carried out with $n$-dodecane as an internal standard, using an Agilent 7820A instrument equipped with a HP-5 column (cross-linked 5\% phenyl silicone gum, $30 \mathrm{~m} \times 0.32 \mathrm{~mm} \times 0.25 \mu \mathrm{m}$ ). Conversion was determined by considering instrument response factors. The GC conditions were: (i) $50{ }^{\circ} \mathrm{C}$ for $5 \mathrm{~min}$, (ii) increase in temperature at a rate of $10^{\circ} \mathrm{C} / \mathrm{min}$ until $150^{\circ} \mathrm{C}$, (iii) isotherm for $5 \mathrm{~min}$, and (iv) temperature increase at $20^{\circ} \mathrm{C} / \mathrm{min}$ until $240^{\circ} \mathrm{C}$; retention times: iodobenzene: $8.7 \mathrm{~min}$; dodecane $11.6 \mathrm{~min}$; benzothiazole: 12.0 ; 2-phenylbenzo[d]thiazole: $23.4 \mathrm{~min}$. The retention time of 2-phenylbenzo[ $d$ ] thiazole was determined with a pure sample of the latter obtained by using 1 as catalyst (Scheme 1) [24]. Elemental analyses were performed by the Service d'Analyses, de Mesures Physiques et de Spectroscopie Optique, Institut de Chimie, UMR 7177, Université de Strasbourg. High-resolution mass spectra were recorded on a Bruker micrOTOF mass spectrometer by the Service the Spectrométrie de Masse, Institut de Chimie, UMR 7177, Université de Strasbourg. Benzothiazole, haloarenes and $n$-dodecane were distilled and stored under argon before use. [NiCpCl(IMes)] (3) [35,36], [ $\mathrm{NiCpCl}(\mathrm{IPr})](4)$ [27,37], [NiCp*Cl(IMes)] (5) [38], and [NiCp(NCMe)(IMes)] $\left(\mathrm{PF}_{6}\right)(6)$ [29] were prepared according to the published methods.

\subsection{Typical Procedure for the Attempted Heteroarylations of Aryl Halides}

An oven-dried Schlenk tube containing a magnetic stir bar was loaded with $3(10 \mathrm{mg}, 0.0216 \mathrm{mmol}$, $5 \mathrm{~mol} \%), \mathrm{LiOt}$-Bu (69 mg, $0.861 \mathrm{mmol}, 1.9$ equiv.), benzothiazole ( $50 \mu \mathrm{L}, 0.459 \mathrm{mmol}, 1.0$ equiv.), iodobenzene ( $75 \mu \mathrm{L}, 0.664 \mathrm{mmol}, 1.4$ equiv.) or $p$-bromotoluene (109 $\mathrm{mg}, 0.637 \mathrm{mmol}, 1.4$ equiv.), $n$-dodecane $(15 \mu \mathrm{L}, 0.066 \mathrm{mmol})$, and 1,4-dioxane $(3 \mathrm{~mL})$, and sealed. The Schlenk tube was then put into an oil bath that was heated up to $140{ }^{\circ} \mathrm{C}$. After $16 \mathrm{~h}$, the reaction medium was cooled down to room temperature, and a sample $(0.1 \mathrm{~mL})$ was removed for GC analysis. The volatiles were then removed under gentle vacuum, and the resulting residue was extracted with diethyl ether and filtered over a small plug of silica (Merck Silica Gel 60-mesh size 40-60 $\mu \mathrm{m}$ ). Diethyl ether was then evaporated and the solid residue analysed by ${ }^{1} \mathrm{H} \mathrm{NMR}$ in $\mathrm{CDCl}_{3}$.

\subsection{Synthesis of $\left[\mathrm{NiCp}\left(\mathrm{C}_{7} \mathrm{H}_{4} \mathrm{NS}\right)(\mathrm{IMes})\right](7)$}

KHMDS (1.2 mL, $0.600 \mathrm{mmol}, 0.5 \mathrm{M}$ in toluene) was added to a solution of 3 ( $200 \mathrm{mg}, 0.431 \mathrm{mmol})$ and benzothiazole $(56 \mu \mathrm{L}, 0.514 \mathrm{mmol})$ in toluene $(12 \mathrm{~mL})$ at room temperature, resulting in a very rapid change of color from red to green. After $12 \mathrm{~h}$, the reaction medium was filtered through a Celite pad and concentrated in vacuo to give a brownish powder that was washed with pentane $(3 \times 10 \mathrm{~mL})$. Re-dissolution of this solid in toluene $(10 \mathrm{~mL})$ and THF $(0.5 \mathrm{~mL})$ and filtration through neutral alumina 
with toluene and toluene/THF (20:1) as successive eluents then afforded a green solution that was evaporated to dryness to give 7 as a green-brown powder (193 mg, $0.343 \mathrm{mmol}, 80 \%)$. Anal. Calcd for $\mathrm{C}_{33} \mathrm{H}_{33} \mathrm{~N}_{3} \mathrm{NiS}: \mathrm{C}, 70.48 ; \mathrm{H}, 5.91 ; \mathrm{N}, 7.47$. Found: $\mathrm{C}, 70.55 ; \mathrm{H}, 5.98 ; \mathrm{N}, 7.80$. HR-MS (ESI): $m / z[\mathrm{M}+\mathrm{H}]^{+}$ calcd for $\mathrm{C}_{33} \mathrm{H}_{34} \mathrm{~N}_{3} \mathrm{NiS} 562.1821$, found 562.1789. ${ }^{1} \mathrm{H} \mathrm{NMR}\left(\mathrm{CDCl}_{3}, 300.13 \mathrm{MHz}\right): \delta 7.58\left(\mathrm{~d},{ }^{3} \mathrm{~J}=8.1\right.$, $\left.1 \mathrm{H}, \mathrm{C}_{7} \mathrm{H}_{4} \mathrm{NS}\right), 7.51\left(\mathrm{~d},{ }^{3} \mathrm{~J}=7.8,1 \mathrm{H}, \mathrm{C}_{7} \mathrm{H}_{4} \mathrm{NS}\right), 7.12\left(\mathrm{~m}, 1 \mathrm{H}, \mathrm{C}_{7} \mathrm{H}_{4} \mathrm{NS}\right), 6.98\left(\mathrm{~m}, 1 \mathrm{H}, \mathrm{C}_{7} \mathrm{H}_{4} \mathrm{NS}\right), 6.91(\mathrm{~s}, 2$ $\mathrm{H}, \mathrm{NCH}), 6.89\left(\mathrm{~s}, 4 \mathrm{H}, m-\mathrm{H}_{\mathrm{Mes}}\right), 4.83\left(\mathrm{~s}, 5 \mathrm{H}, \mathrm{C}_{5} \mathrm{H}_{5}\right), 2.38\left(\mathrm{~s}, 3 \mathrm{H}, p-\mathrm{CH}_{3}\right), 2.10\left(\mathrm{~s}, 6 \mathrm{H}, o-\mathrm{CH}_{3}\right) .{ }^{13} \mathrm{C}\left\{{ }^{1} \mathrm{H}\right\}$ NMR (CDCl $3,75.47 \mathrm{MHz}): \delta 177.9(\mathrm{NCN}), 176.0(\mathrm{NCS}), 155.1\left(\mathrm{C}_{6} \mathrm{H}_{4}-\mathrm{C}(3 \mathrm{a})\right), 140.6\left(\mathrm{C}_{6} \mathrm{H}_{4}-\mathrm{C}(7 \mathrm{a})\right), 138.8$ $\left(p-\mathrm{C}_{\text {Mes }}\right), 136.8$ (ipso- $\left.\mathrm{C}_{\text {Mes }}\right), 135.6$ (o- $\left.\mathrm{C}_{\text {Mes }}\right), 129.1\left(m-\mathrm{C}_{\text {Mes }}\right), 123.5(\mathrm{NCH}), 122.8,120.4,119.5$ and 118.6 $\left(\mathrm{C}_{6} \mathrm{H}_{4}-\mathrm{C}(3,4,5,6)\right), 91.4\left(\mathrm{C}_{5} \mathrm{H}_{5}\right), 21.3\left(p-\mathrm{CH}_{3}\right), 18.5\left(o-\mathrm{CH}_{3}\right)$.

\subsection{Synthesis of $\left[\mathrm{NiCp} *\left(\mathrm{C}_{7} \mathrm{H}_{4} \mathrm{NS}\right)(\mathrm{IMes})\right]$ (8)}

KHMDS ( $0.9 \mathrm{~mL}, 0.450 \mathrm{mmol}, 0.5 \mathrm{M}$ in toluene) was added to a solution of 5 ( $236 \mathrm{mg}, 0.447 \mathrm{mmol})$ and benzothiazole $(48 \mu \mathrm{L}, 0.442 \mathrm{mmol})$ in toluene $(12 \mathrm{~mL})$ at room temperature, resulting in a very rapid change of color from red to olive. After $2 h$, the volatiles were evaporated under vacuum to give a brown residue that was extracted with toluene and loaded on the top an alumina pad $(4 \times 3 \mathrm{~cm})$ that was eluted (i) with toluene to yield a yellow fraction, and (ii) with a toluene/THF mixture (20:1) to yield an olive fraction. The latter was then evaporated to dryness to give 8 as an olive solid ( $34 \mathrm{mg}$, $0.0538 \mathrm{mmol}, 12 \%) .{ }^{1} \mathrm{H}$ NMR $\left(\mathrm{C}_{6} \mathrm{D}_{6}, 300.13 \mathrm{MHz}\right): \delta 7.92\left(\mathrm{~d},{ }^{3} \mathrm{~J}=8.1,1 \mathrm{H}, \mathrm{C}_{7} \mathrm{H}_{4} \mathrm{NS}\right), 7.76\left(\mathrm{~d},{ }^{3} \mathrm{~J}=7.8,1\right.$ $\left.\mathrm{H}, \mathrm{C}_{7} \mathrm{H}_{4} \mathrm{NS}\right), 7.24\left(\mathrm{~m}, 1 \mathrm{H}, \mathrm{C}_{7} \mathrm{H}_{4} \mathrm{NS}\right), 7.02\left(\mathrm{~m}, 1 \mathrm{H}, \mathrm{C}_{7} \mathrm{H}_{4} \mathrm{NS}\right), 6.81\left(\mathrm{~s}, 4 \mathrm{H}, m-\mathrm{H}_{\mathrm{Mes}}\right), 6.00(\mathrm{~s}, 2 \mathrm{H}, \mathrm{NCH})$, $\left.2.23\left(\mathrm{~s}, 3 \mathrm{H}, p-\mathrm{CH}_{3}\right), 2.09\left(\mathrm{~s}, 6 \mathrm{H}, o-\mathrm{CH}_{3}\right), 1.43\left(\mathrm{~s}, 15 \mathrm{H}, \mathrm{C}_{5} M e_{5}\right) .{ }^{13} \mathrm{C}^{1}{ }^{1} \mathrm{H}\right\} \mathrm{NMR}\left(\mathrm{C}_{6} \mathrm{D}_{6}, 125.77 \mathrm{MHz}\right)$ : 8187.4 (NCN), 180.9 (NCS), $157.1\left(\mathrm{C}_{6} \mathrm{H}_{4}-\mathrm{C}(3 \mathrm{a})\right), 141.3\left(\mathrm{C}_{6} \mathrm{H}_{4}-\mathrm{C}(7 \mathrm{a})\right), 138.6\left(o-\mathrm{C}_{\text {Mes }}\right), 138.2\left(p-\mathrm{C}_{\text {Mes }}\right), 137.1$ (ipso- $\left.\mathrm{C}_{\mathrm{Mes}}\right), 129.7\left(m-\mathrm{C}_{\mathrm{Mes}}\right), 124.2(\mathrm{NCH}), 123.5,120.9,120.3$ and $119.8\left(\mathrm{C}_{6} \mathrm{H}_{4}-\mathrm{C}(3,4,5,6)\right), 101.7\left(\mathrm{C}_{5} \mathrm{Me}_{5}\right)$, $21.5\left(p-\mathrm{CH}_{3}\right), 19.4\left(o-\mathrm{CH}_{3}\right), 10.6\left(\mathrm{C}_{5} \mathrm{Me} 5\right)$.

\subsection{Crystallographic Studies}

Single crystals of 7 suitable for X-ray diffraction studies were harvested from a batch of crystals obtained at room temperature from a toluene/pentane (1:3) solution. Diffraction data were collected at 173(2) K on a Bruker APEX II DUO Kappa CCD area detector diffractometer equipped with an Oxford Cryosystem liquid $\mathrm{N}_{2}$ device using Mo-K $\alpha$ radiation $(\lambda=0.71073 \AA)$. The crystal-detector distance was $38 \mathrm{~mm}$. The cell parameters were determined (APEX2 software [51]) from reflections taken from three sets of twelve frames, each at ten seconds exposure. The structures were solved using direct methods with SHELXS-2014 and refined against $F^{2}$ for all reflections using the SHELXL-2014 software [52]. A semi-empirical absorption correction was applied using SADABS [53] in APEX2 [51]: transmission factors: $\mathrm{T}_{\min } / \mathrm{T}_{\max }=0.7423 / 0.9540$. All non-hydrogen atoms were refined with anisotropic displacement parameters, using weighted full-matrix least-squares on $F^{2}$. Hydrogen atoms were included in calculated positions and treated as riding atoms using SHELXL default parameters. A summary of crystal data, data collection parameters, and structure refinements is given in Table S1.

\section{Conclusions}

In summary, we have shown that apart from the $\mathrm{Cp}^{*}$ derivative 5, which shows a little activity, all other tested half-sandwich $\mathrm{Ni}(\mathrm{NHC})$ of general formula $[\mathrm{NiCpL}(\mathrm{NHC})]^{(+)}$complexes are incapable of catalyzing the direct coupling of benzothiazole with aryl halides in the presence of an alkoxide as a base. They instead form a C(2)-metallated benzothiazolyl complex that constitutes a potential energy well that quenches all further reactivity. Although benzothiazolyl complexes are often proposed as possible intermediates in such biaryl couplings, the isolated complex, [ $\mathrm{NiCp}\left(\mathrm{C}_{7} \mathrm{H}_{4} \mathrm{NS}\right)$ (IMes)] (7), is to our knowledge a very rare example of fully characterized C(2)-benzothiazolyl-nickel complex.

Supplementary Materials: The following materials are available online at http:/ /www.mdpi.com/2073-4344/9/ 1/76/s1, Figure S1: ${ }^{1} \mathrm{H}$ NMR spectrum of a "catalytic" reaction medium after $16 \mathrm{~h}$ reaction at $120{ }^{\circ} \mathrm{C}$ in 1 ,4-dioxane 
between benzothiazole and 4-bromotoluene in the presence of 3 (5 mol \%) and LiOtBu, Figure S2: ${ }^{1} \mathrm{H}$ NMR spectrum of a "catalytic" reaction medium after $16 \mathrm{~h}$ reaction at $120^{\circ} \mathrm{C}$ in 1,4-dioxane between benzothiazole and iodobenzene in the presence of $3(5 \mathrm{~mol} \%)$ and $\mathrm{KO}$ Bu, Figure S3. ${ }^{1} \mathrm{H}$ NMR spectrum of a "catalytic" reaction medium after $16 \mathrm{~h}$ reaction at $120^{\circ} \mathrm{C}$ in 1,4-dioxane between benzothiazole and iodobenzene in the presence of 6 and $\mathrm{LiO} t \mathrm{Bu}$, Figure S4: ${ }^{1} \mathrm{H}$ NMR spectrum of $\left[\mathrm{NiCp}\left(\mathrm{C}_{7} \mathrm{H}_{4} \mathrm{NS}\right)(\mathrm{IMes})\right]$, Figure S5: ${ }^{13} \mathrm{C}\left\{{ }^{1} \mathrm{H}\right\}$ NMR spectrum of $\left[\mathrm{NiCp}\left(\mathrm{C}_{7} \mathrm{H}_{4} \mathrm{NS}\right)(\mathrm{IMes})\right]$, Figure S6: ${ }^{1} \mathrm{H}$ NMR spectrum of $\left[\mathrm{NiCp} *\left(\mathrm{C}_{7} \mathrm{H}_{4} \mathrm{NS}\right)(\mathrm{IMes})\right]$, Figure S7: ${ }^{13} \mathrm{C}\left\{{ }^{1} \mathrm{H}\right\} \mathrm{NMR}$ spectrum of [NiCp* $\left(\mathrm{C}_{7} \mathrm{H}_{4} \mathrm{NS}\right)$ (IMes)], Table S1: Crystal data and refinement details of compound 7.

Author Contributions: Experimental work, S.S. and B.d.P.C.; Supervision, M.J.C.; Supervision, writing and editing, V.R.

Funding: This research was sponsored by the Agence Nationale de la Recherche, grant number ANR 2010 JCJC 716 1, by the "Investissements d'avenir" program of the Université de Strasbourg, doctoral fellowship of B.d.P.C., by the CNRS and by the Universite de Strasbourg.

Acknowledgments: We appreciate the assistance of Corinne Bailly in the structural determinations, and that of Franck Ulm in conducting a control experiment.

Conflicts of Interest: The authors declare no conflict of interest. The funders had no role in the design of the study; in the collection, analyses, or interpretation of data; in the writing of the manuscript, or in the decision to publish the results.

\section{Appendix A}

CCDC 1819738 contains the supplementary crystallographic data for compound 7. These data can be obtained free of charge via http:/ / www.ccdc.cam.ac.uk/conts/retrieving.html, or from the Cambridge Crystallographic Data Centre, 12 Union Road, Cambridge CB2 1EZ, UK; Fax: (+44) 1223-336-033; or e-mail: deposit@ccdc.cam.ac.uk.

\section{References}

1. Tasker, S.Z.; Standley, E.A.; Jamison, T.F. Recent advances in homogeneous nickel catalysis. Nature 2014, 509, 299-309. [CrossRef] [PubMed]

2. Ananikov, V.P. Nickel: The "Spirited Horse" of Transition Metal Catalysis. ACS Catal. 2015, 5, 1964-1971. [CrossRef]

3. Henrion, M.; Ritleng, V.; Chetcuti, M.J. Nickel N-Heterocyclic Carbene-Catalyzed C-C Bond Formation: Reactions and Mechanistic Aspects. ACS Catal. 2015, 5, 1283-1302. [CrossRef]

4. Ritleng, V.; Henrion, M.; Chetcuti, M.J. Nickel N-Heterocyclic Carbene-Catalyzed C-Heteroatom Bond Formation, Reduction, and Oxidation: Reactions and Mechanistic Aspects. ACS Catal. 2016, 6, 890-906. [CrossRef]

5. Yamaguchi, J.; Muto, K.; Itami, K. Recent Progress in Nickel-Catalyzed Biaryl Coupling. Eur. J. Org. Chem. 2013, 2013, 19-30. [CrossRef]

6. Johnson, S.A. Nickel complexes for catalytic C-H bond functionalization. Dalton Trans. 2015, 44, 10905-10913. [CrossRef] [PubMed]

7. Chatani, N. Nickel-Catalyzed C-H Bond Functionalization Utilizing an $N, N^{\prime}$-Bidentate Directing Group. In C-H Bond Activation and Catalytic Functionalization II; Topics in Organometallic Chemistry; Dixneuf, P., Doucet, H., Eds.; Springer: Cham, Switzerland, 2015; Volume 56, pp. $19-46$.

8. Pototschnig, G.; Maulide, N.; Schnürch, M. Direct Functionalization of C-H Bonds by Iron, Nickel, and Cobalt Catalysis. Chem. Eur. J. 2017, 23, 9206-9232. [CrossRef] [PubMed]

9. Canivet, J.; Yamaguchi, J.; Ban, I.; Itami, K. Nickel-Catalyzed Biaryl Coupling of Heteroarenes and Aryl Halides/Triflates. Org. Lett. 2009, 11, 1733-1736. [CrossRef]

10. Hachiya, H.; Hirani, K.; Satoh, T.; Miura, M. Nickel-Catalyzed Direct Arylation of Azoles with Aryl Bromides. Org. Lett. 2009, 11, 1737-1740. [CrossRef]

11. Kobayashi, O.; Uraguchi, D.; Yamakawa, T. $\mathrm{Cp}_{2} \mathrm{Ni}-\mathrm{KO} t$-Bu-BEt ${ }_{3}\left(\right.$ or $\left.\mathrm{PPh}_{3}\right)$ Catalyst System for Direct C-H Arylation of Benzene, Naphthalene, and Pyridine. Org. Lett. 2009, 11, 2679-2682. [CrossRef]

12. Yamamoto, T.; Muto, K.; Komiyama, M.; Canivet, J.; Yamaguchi, J.; Itami, K. Nickel-Catalyzed C-H Arylation of Azoles with Haloarenes: Scope, Mechanism, and Applications to the Synthesis of Bioactive Molecules. Chem. Eur. J. 2011, 17, 10113-10122. [CrossRef] 
13. Muto, K.; Yamaguchi, J.; Itami, K. Nickel-Catalyzed C-H/C-O Coupling of Azoles with Phenol Derivatives. J. Am. Chem. Soc. 2012, 134, 169-172. [CrossRef] [PubMed]

14. Muto, K.; Yamaguchi, J.; Lei, A.; Itami, K. Isolation, Structure, and Reactivity of an Arylnickel(II) Pivalate Complex in Catalytic C-H/C-O Biaryl Coupling. J. Am. Chem. Soc. 2013, 135, 16384-16387. [CrossRef] [PubMed]

15. Wang, J.; Ferguson, D.M.; Kalyani, D. Nickel-catalyzed intramolecular C-H arylation using aryl pivalates as electrophiles. Tetrahedron 2013, 69, 5780-5790. [CrossRef]

16. Xu, H.; Muto, K.; Yamaguchi, J.; Zhao, C.; Itami, K.; Musaev, D.G. Key Mechanistic Features of Ni-Catalyzed C-H/C-O Biaryl Coupling of Azoles and Naphthalen-2-yl Pivalates. J. Am. Chem. Soc. 2014, 136, 14834-14844. [CrossRef]

17. Muto, K.; Hatakeyama, T.; Yamaguchi, J.; Itami, K. C-H arylation and alkenylation of imidazoles by nickel catalysis: Solvent-accelerated imidazole C-H activation. Chem. Sci. 2015, 6, 6792-6798. [CrossRef]

18. Wang, Y.; Wu, S.-B.; Shi, W.-J.; Shi, Z.-J. C-O/C-H Coupling of Polyfluoroarenes with Aryl Carbamates by Cooperative Ni/Cu Catalysis. Org. Lett. 2016, 18, 2548-2551. [CrossRef]

19. Amaike, K.; Muto, K.; Yamaguchi, J.; Itami, K. Decarbonylative C-H Coupling of Azoles and Aryl Esters: Unprecedented Nickel Catalysis and Application to the Synthesis of Muscoride A. J. Am. Chem. Soc. 2012, 134, 13573-13576. [CrossRef]

20. Kruckenberg, A.; Wadepohl, H.; Gade, L.H. Bis(diisopropylphosphinomethyl)amine Nickel(II) and Nickel(0) Complexes: Coordination Chemistry, Reactivity, and Catalytic Decarbonylative $\mathrm{C}-\mathrm{H}$ Arylation of Benzoxazole. Organometallics 2013, 32, 5153-5170. [CrossRef]

21. Meng, L.; Kamada, Y.; Muto, K.; Yamaguchi, J.; Itami, K. C-H Alkenylation of Azoles with Enols and Esters by Nickel Catalysis. Angew. Chem. Int. Ed. 2013, 52, 10048-10051. [CrossRef]

22. Soni, V.; Jagtap, R.A.; Gonnade, R.G.; Punji, B. Unified Strategy for Nickel-Catalyzed C-2 Alkylation of Indoles through Chelation Assistance. ACS Catal. 2016, 6, 5666-5672. [CrossRef]

23. Patel, U.N.; Jain, S.; Pandey, D.K.; Gonnade, R.G.; Vanka, K.; Punji, B. Mechanistic Aspects of Pincer Nickel(II)-Catalyzed C-H Bond Alkylation of Azoles with Alkyl Halides. Organometallics 2018, 37, 1017-1025. [CrossRef]

24. de Cardoso, B.P.; Bernard-Schaaf, J.-M.; Shahane, S.; Veiros, L.F.; Chetcuti, M.J.; Ritleng, V. Displacement of $\eta^{5}$-cyclopentadienyl ligands from half-sandwich C,C-(NHC-cyanoalkyl)-nickel(II) metallacycles: Further insight into the structure of the resulting $\mathrm{Cp}$-free nickelacycles and a catalytic activity study. Dalton Trans. 2018, 47, 1535-1547. [CrossRef] [PubMed]

25. Henrion, M.; Oertel, A.M.; Ritleng, V.; Chetcuti, M.J. Facile displacement of $\eta^{5}$-cyclopentadienyl ligands from half-sandwich alkyl,NHC-nickel complexes: An original route to robust $c i s-\mathrm{C}, \mathrm{C}$-nickel square planar complexes. Chem. Commun. 2013, 49, 6424-6426. [CrossRef] [PubMed]

26. Oertel, A.M.; Freudenreich, J.; Gein, J.; Ritleng, V.; Veiros, L.F.; Chetcuti, M.J. Intramolecular Nitrile C-H Bond Activation in Nickel NHC Complexes: A Route to New Nickelacycles. Organometallics 2011, 30, 3400-3411. [CrossRef]

27. Kelly, R.A., III; Scott, N.M.; Díez-González, S.; Stevens, E.D.; Nolan, S.P. Simple Synthesis of CpNi(NHC)Cl Complexes (Cp = Cyclopentadienyl; NHC = N-Heterocyclic Carbene). Organometallics 2005, 24, 3442-3447. [CrossRef]

28. Macklin, T.K.; Snieckus, V. Directed Ortho Metalation Methodology. The $N, N$-Dialkyl Aryl O-Sulfamate as a New Directed Metalation Group and Cross-Coupling Partner for Grignard Reagents. Org. Lett. 2005, 7, 2519-2522. [CrossRef] [PubMed]

29. Ritleng, V.; Oertel, A.M.; Chetcuti, M.J. Half-sandwich NHC-nickel(II) complexes as pre-catalysts for the fast Suzuki coupling of aryl halides: A comparative study. Dalton Trans. 2010, 39, 8153-8160. [CrossRef]

30. Malyshev, D.A.; Scott, N.M.; Marion, N.; Stevens, E.D.; Ananikov, V.P.; Beletskaya, I.P.; Nolan, S.P. Homogeneous Nickel Catalysts for the Selective Transfer of a Single Arylthio Group in the Catalytic Hydrothiolation of Alkynes. Organometallics 2006, 25, 4462-4470. [CrossRef]

31. Bheeter, L.P.; Henrion, M.; Chetcuti, M.J.; Darcel, C.; Ritleng, V.; Sortais, J.-B. Cyclopentadienyl N-heterocyclic carbene-nickel complexes as efficient pre-catalysts for the hydrosilylation of imines. Catal. Sci. Technol. 2013, 3, 3111-3116. [CrossRef]

32. Landers, B.; Navarro, O. Microwave-assisted synthesis of (N-heterocyclic carbene)Ni(Cp)Cl complexes. Inorg. Chim. Acta 2012, 380, 350-353. [CrossRef] 
33. Banach, Ł.; Guńka, P.A.; Górska, D.; Podlewska, M.; Zachara, J.; Buchowicz, W. Synthesis, Structures and Properties of Half-Sandwich Nickel(II) Complexes with Backbone-Modified NHC Ligands. Eur. J. Inorg. Chem. 2015, 5677-5686. [CrossRef]

34. Henrion, M.; Chetcuti, M.J.; Ritleng, V. From acetone metalation to the catalytic $\alpha$-arylation of acyclic ketones with NHC-nickel(II) complexes. Chem. Commun. 2014, 50, 4624-4627. [CrossRef] [PubMed]

35. Abernethy, C.D.; Cowley, A.H.; Jones, R.A. Reaction of nickelocene with 1,3-dimesitylimidazolium chloride. J. Organomet. Chem. 2000, 596, 3-5. [CrossRef]

36. Ritleng, V.; Brenner, E.; Chetcuti, M.J. Preparation of a N-Heterocyclic Carbene Nickel(II) Complex. J. Chem. Educ. 2008, 85, 1646-1648. [CrossRef]

37. Cooke, J.; Lightbody, O.C. Optimized syntheses of cyclopentadienyl nickel chloride compounds containing $\mathrm{N}$-heterocyclic carbene ligands for short laboratory periods. J. Chem. Educ. 2011, 88, 88-91. [CrossRef]

38. Ritleng, V.; Barth, C.; Brenner, E.; Milosevic, S.; Chetcuti, M.J. Synthesis, Structure, and Solution Dynamics of Pentamethylcyclopentadienyl Nickel Complexes Bearing N-Heterocyclic Carbene Ligands. Organometallics 2008, 27, 4223-4228. [CrossRef]

39. Khake, S.M.; Soni, V.; Gonnade, R.G.; Punji, B. Design and development of POCN-pincer palladium catalysts for C-H bond arylation of azoles with aryl iodides. Dalton Trans. 2014, 43, 16084-16096. [CrossRef]

40. Khake, S.M.; Jagtap, R.A.; Dangat, Y.B.; Gonnade, R.G.; Vanka, K.; Punji, B. Mechanistic Insights into Pincer-Ligated Palladium-Catalyzed Arylation of Azoles with Aryl Iodides: Evidence of a Pd ${ }^{\mathrm{II}}-\mathrm{Pd}^{\mathrm{IV}}-\mathrm{Pd}^{\mathrm{II}}$ Pathway. Organometallics 2016, 35, 875-886. [CrossRef]

41. Wang, C.; Li, Y.; Lu, B.; Hao, X.-Q.; Gong, J.-F.; Song, M.-P. (Phosphinito)aryl benzimidazole PCN pincer palladium(II) complexes: Synthesis, characterization and catalytic activity in CAH arylation of azoles with aryl iodides. Polyhedron 2018, 143, 184-192. [CrossRef]

42. Itoh, T.; Mase, T. A Novel Practical Synthesis of Benzothiazoles via Pd-Catalyzed Thiol Cross-Coupling. Org. Lett. 2007, 9, 3687-3689. [CrossRef]

43. Herrmann, W.A.; Runte, O.; Artus, G. Synthesis and structure of an ionic beryllium-“carbene" complex. J. Organomet. Chem. 1995, 501, C1-C4. [CrossRef]

44. Baker, M.V.; Barnard, P.J.; Brayshaw, S.K.; Hickey, J.L.; Skelton, B.W.; White, A.H. Synthetic, structural and spectroscopic studies of (pseudo)halo(1,3-di-tert-butylimidazol-2-ylidine)gold complexes. Dalton Trans. 2005, 37-43. [CrossRef] [PubMed]

45. Chernyshova, E.S.; Goddard, R.; Pörschke, K.-R. Mononuclear NHC-Pd- $\pi$-Allyl Complexes Containing Weakly Coordinating Ligands. Organometallics 2007, 26, 3236-3251. [CrossRef]

46. Teng, Q.; Huynh, H.V. A unified ligand electronic parameter based on ${ }^{13} \mathrm{C}$ NMR spectroscopy of N-heterocyclic carbene complexes. Dalton Trans. 2017, 46, 614-627. [CrossRef] [PubMed]

47. Oertel, A.M.; Ritleng, V.; Burr, L.; Chetcuti, M.J. Synthesis and Structural Characterization of Half-Sandwich Nickel Complexes Bearing Two Different N-Heterocyclic Carbene Ligands. Organometallics 2011, 30, 6685-6691. [CrossRef]

48. Yokota, A.; Aihara, Y.; Chatani, N. Nickel(II)-Catalyzed Direct Arylation of C-H Bonds in Aromatic Amides Containing an 8-Aminoquinoline Moiety as a Directing Group. J. Org. Chem. 2014, 79, 11922-11932. [CrossRef]

49. Matsubara, K.; Ueno, K.; Shibata, Y. Synthesis and Structures of Nickel Halide Complexes Bearing Monoand Bis-coordinated N-Heterocyclic Carbene Ligands, Catalyzing Grignard Cross-Coupling Reactions. Organometallics 2006, 25, 3422-3427. [CrossRef]

50. Martin, A.M.; Makida, Y.; Meiries, S.; Slawin, A.M.Z.; Nolan, S.P. Enhanced Activity of [Ni(NHC)CpCl] Complexes in Arylamination Catalysis. Organometallics 2013, 32, 6265-6270. [CrossRef]

51. M86-E01078 APEX2 User Manual; Bruker AXS Inc.: Madison, WI, USA, 2006.

52. Sheldrick, G.M. A short history of SHELX. Acta Cryst. 2008, 64, 112-122. [CrossRef]

53. Sheldrick, G.M. SADABS, Program for Empirical Absorption Correction; University of Göttingen: Göttingen, Germany, 1996

(C) 2019 by the authors. Licensee MDPI, Basel, Switzerland. This article is an open access article distributed under the terms and conditions of the Creative Commons Attribution (CC BY) license (http:/ / creativecommons.org/licenses/by/4.0/). 